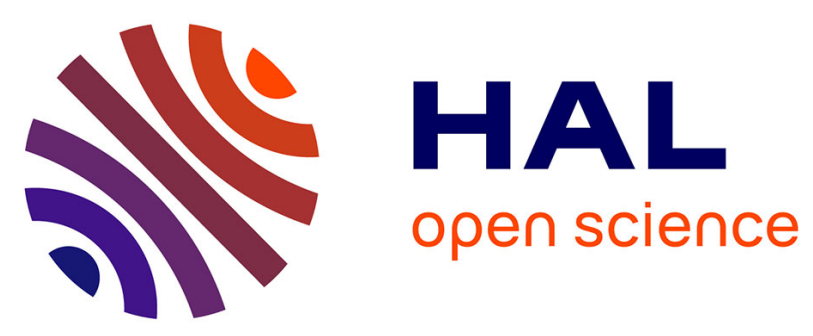

\title{
Microstructured Nematic Liquid Crystalline Elastomer Surfaces with Switchable Wetting Properties
}

\author{
Zi Liang Wu, Axel Buguin, Hong Yang, Jean-Marie Taulemesse, Nicolas Le \\ Moigne, Anne Bergeret, Xiaogong Wang, Patrick Keller
}

\section{- To cite this version:}

Zi Liang Wu, Axel Buguin, Hong Yang, Jean-Marie Taulemesse, Nicolas Le Moigne, et al.. Microstructured Nematic Liquid Crystalline Elastomer Surfaces with Switchable Wetting Properties. Advanced Functional Materials, 2013, 23 (24), pp.3070-3076. 10.1002/adfm.201203291 . hal-03247385

\section{HAL Id: hal-03247385 \\ https://hal.mines-ales.fr/hal-03247385}

Submitted on 3 Jun 2021

HAL is a multi-disciplinary open access archive for the deposit and dissemination of scientific research documents, whether they are published or not. The documents may come from teaching and research institutions in France or abroad, or from public or private research centers.
L'archive ouverte pluridisciplinaire HAL, est destinée au dépôt et à la diffusion de documents scientifiques de niveau recherche, publiés ou non, émanant des établissements d'enseignement et de recherche français ou étrangers, des laboratoires publics ou privés. 


\title{
Microstructured Nematic Liquid Crystalline Elastomer Surfaces with Switchable Wetting Properties
}

\author{
Zi Liang Wu, Axel Buguin, Hong Yang, Jean-Marie Taulemesse, Nicolas Le Moigne, \\ Anne Bergeret, Xiaogong Wang, and Patrick Keller*
}

\begin{abstract}
Inspired by the lotus leaf, scientists have developed many superhydrophobic surfaces, some of which show remarkable switching between hydrophobic and hydrophilic state under external stimuli. However, the switch usually relies on the change of chemical properties rather than on the modification of the topographic structure of the surface. In this paper, the roughness-changerelated switchable wetting properties of microstructured responsive surfaces made of nematic liquid crystalline elastomers (LCEs) is reported. First, various carbonate LC monomers and side-on LCEs are synthesized with low nematic-to-isotropic transition temperature, $T_{\mathrm{Nl}}$. Then, LCEs prepared from 3"-vinylcarbonyloxypropyl 2,5-di(4'-octyloxybenzoyloxy)benzoate monomer, with $T_{\mathrm{NI}}$ of $76^{\circ} \mathrm{C}$ and contraction of $34 \%$ are used to construct a surface covered with micropillar arrays by using a replica molding technique. The contraction of the micropillars induces a reversible roughness change of the microstructured surface. Water contact angle of this microstructured surface changed with temperature, indicating a successful approach at building a surface with switchable wetting properties.
\end{abstract}

\section{Introduction}

Nature has developed myriad functional materials, which serve as excellent paradigms for scientists to create new materials and devices. ${ }^{[1,2]}$ The functionalities of the natural materials are very

Dr. Z. L. Wu, Prof. A. Buguin, Dr. P. Keller

Institut Curie

Centre de Recherche

CNRS UMR 168

Université Pierre et Marie Curie

26 rue d'Ulm 75248 Paris cedex 05, France

E-mail: Patrick.keller@curie.fr

Prof. H. Yang

School of Chemistry and Chemical Engineering

Southeast University

Nanjing 211189, China

Dr. J.-M. Taulemesse, Dr. N. Le Moigne, Prof. A. Bergeret

Centre des Matériaux (C2MA)

Ecole des Mines d'Alès

6 avenue de Clavières 30319 Alès cedex, France

Prof. X. Wang

Department of Chemical Engineering

Laboratory for Advanced Materials

Tsinghua University

Beijing, 100084, China often associated with specific micro- and nanostructured surfaces, ${ }^{[2]}$ such as for the self-cleaning properties of the lotus leaves or the vivid colors of the butterfly wings. ${ }^{[2 a-c]}$ For example, inspired by lotus leaf, many organic as well as inorganic structured surfaces with superhydrophobicity have been prepared. ${ }^{[3,4]}$ Furthermore, some of them, fabricated or coated with responsive polymers or inorganic nano-materials, showed switchable properties from hydrophobic to hydrophilic under suitable stimuli. ${ }^{[4]}$ However, the switching mainly originated from the change of chemical properties rather than from the change of topographic structure of the surface.

In this paper, we present our first attempt at making microstructured responsive surfaces for which large surface roughness changes could be induced by external stimuli. This approach might give us the opportunity to better control the physical properties of the surfaces, such as the wetting and the adhesion. ${ }^{[5]}$

Nematic liquid crystalline elastomers (LCEs) as a classic responsive soft material have been recognized as one of the best systems to develop artificial muscles and soft actuators. ${ }^{[6]}$ These materials combine the anisotropic structure of liquid crystals and the elasticity of the elastomers, exhibiting reversible, anisotropic shape change under external stimuli, such as light and temperature. The motor for the contraction is the reversible shape change of the macromolecular chain, from stretched to coiled, that occurs at the nematic-to-isotropic (N-I) phase transition. ${ }^{[6,7]} \mathrm{A}$ considerable amount of work aiming at preparing macroscopic LCEs and using them to create different kinds of soft actuators and sensors has been published. ${ }^{[6,8]} \mathrm{A}$ seminal two-stage procedure to prepare monodomain nematic polysiloxane LCEs developed by Finkelmann et al. ${ }^{[8 a]}$ has been used in hundreds of papers up to now. The orientation is achieved under strain by a simple extension before the material is fully crosslinked. Thus obtained LCEs usually exhibit large contractions up to $\sim 300 \%$ and low nematic-to-isotropic phase transition temperatures, $T_{\mathrm{NI}}$, due to the flexible siloxane backbone used. However, this method is limited to the preparation of macroscopic LCE samples. An alternative method is to synthesize LCEs by thermal or photo-initiated radical polymerization of liquid crystalline (LC) monomers. ${ }^{[6 b, 8 b]}$ Magnetic field or surface effects are usually used to align the mesogens 
before the polymerization and crosslinking reaction. Compared with the method of two-step crosslinking, photo-initiated radical polymerization, which can be combined with microfl uidics, soft-lithography, and photolithography, has overwhelming advantages to create micrometer-sized LCE actuators.

Several groups have developed new approaches to produce micron-size actuators based on LCEs. ${ }^{[9-11]}$ Ohm et al. used a microfl uidic device coupled with UV lamp for photopolymerization to prepare LCE microparticles, which changed their shape from sphere to ellipse when heated above the $T_{\mathrm{NI}}$ of the LCE. ${ }^{[10]}$ We applied a replica molding technique to produce surfaces covered with micrometer-sized pillars based on side-on and main-chain LCEs, which showed reversible shape changes. ${ }^{[11]}$ However, until now, the photopolymerization approach has produced thermotropic LCEs with relatively high $T_{\mathrm{NI}}$, over $120^{\circ} \mathrm{C},{ }^{[9-11]}$ greatly limiting the applications of these micrometer-sized LCEs in microfl uidics or responsive surfaces. Therefore, keeping in mind our objective to build microstructured responsive surfaces with adjustable wetting properties, we designed and synthesized LC monomers, which could give nematic LCEs with low $T_{\mathrm{NI}}$ and large contraction.

In this article, we report the synthesis of vinyl carbonate and allyl carbonate side-on nematic monomers and LCEs with low $T_{\mathrm{NI}}$, up to $70{ }^{\circ} \mathrm{C}$, and the construction of responsive structured surfaces based on these LCEs. Water contact angle measurements as a function of temperature have been performed for the microstructured surfaces, showing significant reversible changes above and below the $T_{\mathrm{NI}}$ of the LCEs.

\section{Results and Discussion}

Following the synthetic route of Figure 1, we successfully obtained the target carbonate LC monomers, as confirmed by ${ }^{1} \mathrm{H}$ NMR spectra and elemental analysis (Figure S1, Figure S2, and Table S1 in the Supporting Information). Although all the new synthesized monomers showed nematic phase in a certain temperature range, the properties of the monomers needed to be further investigated regarding whether they were photopolymerizable to prepare LCEs, as well as for the quality of the resultant LCEs, i.e., their $\mathrm{T}_{\mathrm{NI}}$ and contraction. We first studied the effect of several chemical structure variations on the physical properties of the carbonate monomers, and then selected the most promising ones to prepare the responsive structured surfaces.

The monomers are noted as $\operatorname{VC} x(n=\gamma)$ or $\mathrm{ACx}(n=\gamma)$, where $\mathrm{V}$ or A indicates vinyl or allyl monomer, $x$ and $y$ are the number of carbon in the end alkyl chains and in the linked alkyl chain (between the benzoate group and carbonate group), respectively.

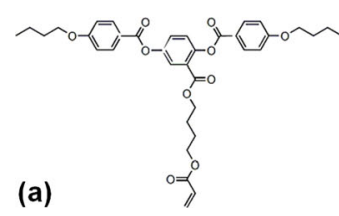

(b)

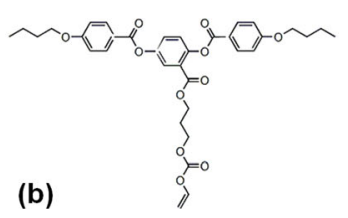

(c)

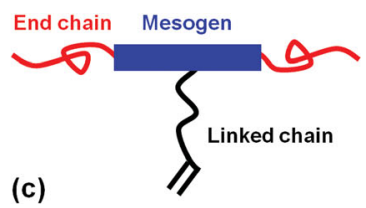

Figure 2. a,b) Molecular structure of A444 (a) and VC4 $(n=3)$ (b). c) Typical structure of synthesized monomers. After polymerization, they form side-on LCEs. 
Table 1. Phase transition temperatures of the synthesized alkylene carbonate monomers.

\begin{tabular}{|c|c|c|c|}
\hline Sample & $\begin{array}{l}\text { Phase transition temperature }{ }^{\mathrm{a})} \\
{\left[{ }^{\circ} \mathrm{C}\right]}\end{array}$ & $\begin{array}{c}\Delta \mathrm{H}_{N 1} \mathrm{~b}^{2} \\
{[\mathrm{~J} / \mathrm{g}]}\end{array}$ & $\begin{array}{l}\mathrm{T}_{\mathrm{N}} \mathrm{C}^{\mathrm{c})} \\
{\left[{ }^{\circ} \mathrm{C}\right]}\end{array}$ \\
\hline VC4 $(n=2)$ & K 80.5 N 99.3 I & 1.74 & 100 \\
\hline AC4 $(n=2)$ & K 59.1 N 91.3 I & 2.11 & 92.9 \\
\hline $\operatorname{VC} 4(n=3)$ & K 63.8 N 89.2 I & 1.53 & 91 \\
\hline AC4 $(n=3)$ & K 57.6 N 86.8 I & 1.54 & 87.7 \\
\hline $\operatorname{VC} 4(n=6)$ & K 45.6 N 79.1 I & 1.13 & 79 \\
\hline AC4 $(n=6)$ & K 39.7 N 70.8 I & 1.35 & 71.3 \\
\hline $\operatorname{VC} 8(n=3)$ & K 59.9 N 83.1 I & 1.59 & 83.2 \\
\hline AC8 $(n=3)$ & K 38 N 72.3 I & 1.38 & 73.8 \\
\hline $\operatorname{VC10}(n=3)$ & K 55.7 N 80 I & 1.76 & 80 \\
\hline $\mathrm{ACl0}(n=3)$ & K 48.6 N 72.3 I & 1.44 & 72.5 \\
\hline
\end{tabular}

a) Transition temperatures were obtained from the second heating scan of differential scanning calorimetry (DSC) thermograms of the monomers; heating rate: $5{ }^{\circ} \mathrm{C} /$ min. K: crystalline; $\mathrm{N}$ : nematic; I: isotropic; ${ }^{b)}$ Enthalpy associated with the $\mathrm{N}-\mathrm{I}$ phase transition of the monomers, $\Delta \mathrm{H}_{\mathrm{N}}$, was calculated from the corresponding peak of the DSC thermograms; ${ }^{\mathrm{c}} T_{\mathrm{N}}$ was measured by observation of the $\mathrm{N}$-I phase transition under polarizing optical microscope.

shorter than that of A444 $(n=4)$, the $T_{\mathrm{NI}}$ was $89.2^{\circ} \mathrm{C}$ (Table 1 ), $\sim 10{ }^{\circ} \mathrm{C}$ lower than that of A444. The allyl carbonate monomer, 3"-allylcarbonyloxypropyl 2,5-di(4'-butyloxybenzoyloxy)benzoate (AC4 $(n=3)$ ) had a lower $T_{\mathrm{NI}}$ of $86.8{ }^{\circ} \mathrm{C}$. This result indicated that the introduction of a carbonate group can effectively decrease the $\mathrm{T}_{\mathrm{NI}}$ of the LC monomers, compared with acrylate LC monomer. The carbonate group introduces more decoupling between the rigid $\mathrm{C}-\mathrm{C}$ double bond and the poly(methylene) spacer, bringing in more disorder, thus weakening the intermolecular interactions between mesogenic groups and reducing the stability of the nematic mesophase.

The vinyl carbonate LC monomers could be successfully photopolymerized to form LCPs, or copolymerized with chemical crosslinker to form LCE films, whereas the allyl ones could not, even after UV irradiation during extended time. All obtained LCE films showed reversible contraction at the N-I phase transition; as shown in Figure 3, E-VC4 $(n=3)$ with $10 \mathrm{~mol} \%$ crosslinker had a contraction of $37 \%$, comparable to $33 \%$ of E-A444 (Table 2). When the crosslinker concentration was increased to $20 \mathrm{~mol} \%$, the contraction of E-VC4 $(n=3)$ decreased to $28 \%$.
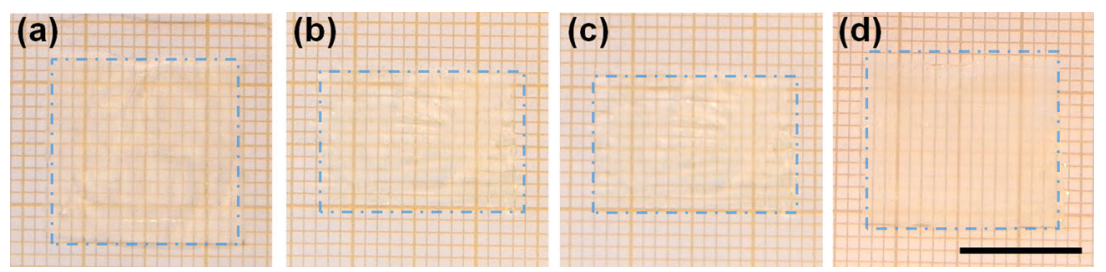

Figure 3. Images of LCE film (E-VC4 $(n=3), 10$ mol\% crosslinker) demonstrating the reversible contraction. The LCE film, floating on silicone oil, was heated to a) $50^{\circ} \mathrm{C}$, b) $95^{\circ} \mathrm{C}$, c) $110^{\circ} \mathrm{C}$, and then cooled back to d) $40^{\circ} \mathrm{C}$. The dotted line rectangles which outline the shape of the LCE film are drawn as a visual guide. Scale bar: $1 \mathrm{~cm}$.
Table 2. Contraction and $T_{\mathrm{N} I}$ of LCEs and $T_{\mathrm{N} I}$ of LCPs.

\begin{tabular}{lcccc}
\hline Sample & Contraction & $\begin{array}{c}\mathrm{T}_{\mathrm{N} I, L \mathrm{LE} / L \mathrm{LCP})} \\
{\left[{ }^{\circ} \mathrm{C}\right]}\end{array}$ & $\begin{array}{c}\Delta \mathrm{H}_{\mathrm{NI}} \\
{[/ \mathrm{g}]}\end{array}$ & $\begin{array}{c}\mathrm{T}_{\mathrm{NI}, \mathrm{LCE} / \mathrm{LCP}}-\mathrm{T}_{\mathrm{N}, \mathrm{M}}{ }^{\mathrm{b})} \\
{\left[{ }^{\circ} \mathrm{C}\right]}\end{array}$ \\
\hline E-A444 & $33 \%$ & 124.7 & 1.68 & 26.4 \\
E-VC4 $(n=3)$ & $37 \%$ & 90.1 & 1.62 & 0.9 \\
E-VC4 $(n=2)$ & $41 \%$ & 97.1 & 1.75 & -2.2 \\
E-VC4 $(n=6)$ & $27 \%$ & 85.7 & 1.44 & 6.6 \\
E-VC8 $(n=3)$ & $34 \%$ & 76 & 1.21 & -6.9 \\
E-VC10 $(n=3)$ & $16 \%$ & 70.8 & 0.93 & -9.2 \\
P-A444 & - & 128.7 & 3.23 & 30.4 \\
P-VC4 $(n=3)$ & - & 94 & 2.2 & 4.8 \\
P-VC8 $(n=3)$ & - & 79.3 & 1.19 & -3.6 \\
P-VC10 $(n=3)$ & - & 73.6 & 1.01 & -6.4 \\
\hline
\end{tabular}

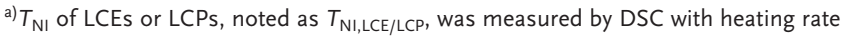
of $5^{\circ} \mathrm{C} / \mathrm{min}$; ${ }^{\text {b) }} T_{\mathrm{NI}}$ of the monomer was noted as $T_{\mathrm{N} 1, \mathrm{M}}$ here to distinguish it from $T_{\mathrm{N} I, L C E / L C P}$.

The effect of carbonate group on $T_{\mathrm{NI}}$ is even more evident in LCPs and LCEs. The $\mathrm{T}_{\mathrm{NI}}$ of E-VC4 $(n=3)$ is $90.1^{\circ} \mathrm{C}$, just $0.9^{\circ} \mathrm{C}$ higher than for the monomer. By contrast, $T_{\mathrm{NI}}$ of E-A444 is $124.7^{\circ} \mathrm{C}, 26.4{ }^{\circ} \mathrm{C}$ higher than that of monomer (Table 2). A similar situation is found for the glass transition temperatures, $T_{\mathrm{g}}$, of the LCPs, P-A444 and P-VC4 $(n=3)$, which have the same mesogen and similar spacer length. P-VC4 $(n=3)$ has a $T_{\mathrm{g}}$ of $\sim 26^{\circ} \mathrm{C}$, much lower than that of P-A $444, T_{\mathrm{g}}$ of $\sim 50^{\circ} \mathrm{C}$ (Supporting Information Figure S3), indicating that P-VC4 $(n=3)$ possesses a relatively flexible polymer backbone. ${ }^{[12,13]}$

\subsubsection{Effect of the Spacer and of the Terminal Chain Lengths on the Stability of the Nematic Mesophase}

The synthesized monomers share a common structure, a rodlike mesogen with two end grafted chains and a middle grafted chain which includes the reactive $\mathrm{C}-\mathrm{C}$ double bond (Figure $2 \mathrm{c}$ ). Either an increase in the flexible end chain length or the middle grafted chain length should bring more molecular disorder; thus, the intermolecular interaction should be weakened, decreasing the transition temperatures.

We first studied the effect of the spacer length, i.e., the number of $\mathrm{CH}_{2}$ group, $n$, between the carbonate group and the benzoate group, on the $T_{\mathrm{NI}}$ of the LC monomers. Three kinds of vinyl carbonate monomers, VC4 $(n=2,3,6)$, were synthesized with the same mesogen part, as well as the same end chains grafted on the mesogen. As $n$ increased, both the melting temperature, $T_{\mathrm{m}}$, and $T_{\mathrm{NI}}$ decreased (Figure 4a and Table 1) (DSC thermograms for $\operatorname{VC} 4(n=2)$ and VC4 $(n=$ 3) show an extra exotherm peak at temperature around 20 and $10{ }^{\circ} \mathrm{C}$, respectively. Those peaks are related to the partial recrystallization on heating of the compounds, which remain in the nematic supercooled phase for extended times). $T_{\mathrm{NI}}$ of $\mathrm{VC} 4$ decreased from $99.3^{\circ} \mathrm{C}$ for $n=2$ to $79.1{ }^{\circ} \mathrm{C}$ for $n=6$. This effect was also found in the acrylate LC 
(a)

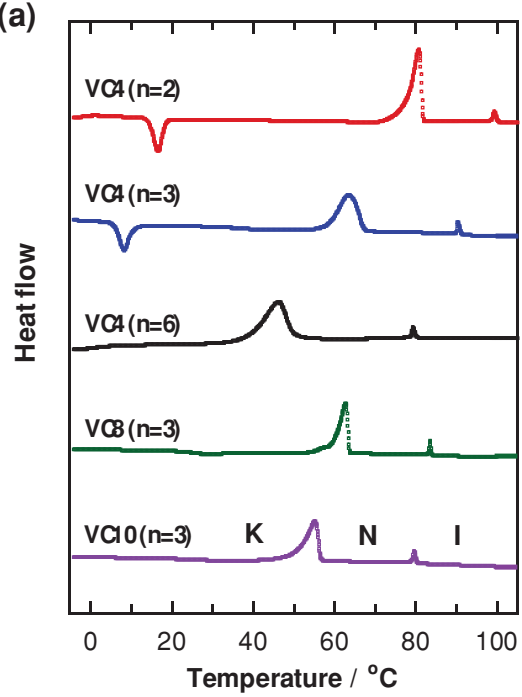

(b)

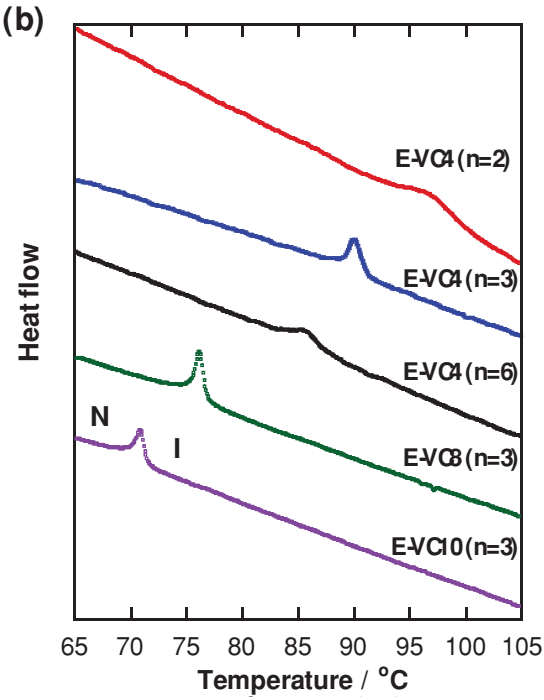

actuators. They are perfectly suitable for our goal of preparing responsive surfaces whose roughness could be adjusted by an external physical stimulus.

\subsection{Responsive Surfaces with Adjustable Roughness}

Microtextured surfaces were prepared by a technique combining the specific properties of a nematic mesophase (such as alignment by a magnetic field) with a soft-lithography approach to prepare the PDMS molds, following a protocol described in ref. [11] After removing the mold, well-arranged micropillars were left on the surface of LCEs, as shown in Figure 5. For the structured surface of E-VC4 $(n=3)$ (Figure 5a,b), the pillars had dimension of diameter $=20 \mu \mathrm{m}$, length $=$ $75 \mu \mathrm{m}$, and spacing $=60 \mu \mathrm{m}$. Under external stimulus, i.e., raising the temperature above

Figure 4. a) DSC thermograms of five vinyl carbonate LC monomers and b) their LCEs. Heating rate: $5{ }^{\circ} \mathrm{C} / \mathrm{min}$.

monomers. ${ }^{[12 c, 14]}$ The same tendency was observed in the corresponding LCEs (Figure $4 \mathrm{~b}$ ).

We should point out that a large $n$ is detrimental to the coupling of the side-on mesogens and the backbone in the LCEs after polymerization. For side-on LCEs, the length of the spacer, which connects the backbone and the laterally grafted mesogens, is crucial for the extent of the reversible contraction of LCEs. The motor for contraction of LCEs is the conformational change occurring at the level of the polymer backbone at the N-I phase transition: due to the influence of the nematic order on the polymer chain, the backbone adopts an anisotropic conformation. ${ }^{[7]}$ If this coupling is weakened, the related LCE will have a smaller contraction. Indeed, the E-VC4 $(n=6)$ has a contraction of $27 \%$, much lower than $41 \%$ for E-VC4 $(n=2)$ (Table 2). Considering the effect of $n$ on $T_{\mathrm{NI}}$ and the contraction of the LCEs, we set $n=3$ and studied the effect of the terminal chain length on the $T_{\mathrm{NI}}$ of the vinyl carbonate monomers.

We synthesized monomers with butyloxy, octyloxy, and decyloxy as the end chains. As expected, both $T_{\mathrm{m}}$ and $T_{\mathrm{NI}}$ decreased with the increase in the length of end chains (Figure $4 \mathrm{a}$ and Table 1). 3"-vinylcarbonyloxypropyl 2,5-di(4'-decyloxybenzoyloxy) benzoate, $\operatorname{VC10}(n=3)$, had a $\mathrm{T}_{\mathrm{NI}}$ as low as $80^{\circ} \mathrm{C}$. Increase in the end chains also weakened the intermolecular interactions, and therefore decreased the $T_{\mathrm{NI}}$ of monomers, as well as $T_{\mathrm{NI}}$ of the LCEs (Figure $4 \mathrm{~b}$ and Table 2). ${ }^{[15]}$

Based on the above results, it was clear that (i) the introduction of carbonate group instead of ester group could effectively decrease $T_{\mathrm{NI}}$ of the related side-on LCEs, lower than $100{ }^{\circ} \mathrm{C}$, because the $\mathrm{C}-\mathrm{O}$ bond of carbonate group provided more free rotation; (ii) the spacer length increase weakened the coupling between mesogen and backbone and decreased the contraction of LCEs, although it could lower the $\mathrm{T}_{\mathrm{NI}}$ of LCEs; (iii) lengthening of the chains which were grafted on two ends of the mesogen could lower the $T_{\mathrm{NI}}$ of LCEs, without decreasing too much the contraction of LCEs.

These side-on LCEs with considerable contraction and low $T_{\mathrm{NI}}$ are ideal materials for developing artificial muscles and soft
$T_{\mathrm{NI}}$, the pillars on the LCE surface contracted along their long axis and in a direction perpendicular to the surface. To better observe their contraction, the pillars were cut off from the surface with a razor blade. During the heating-cooling cycles, the pillars showed a reversible contraction, as shown in Figure 6. When the temperature was above $T_{\mathrm{NI}}$ of the E-VC4 $(n=3)$, $90.1^{\circ} \mathrm{C}$, the birefringence of the pillars disappeared, indicating that the contraction was related to the N-I phase transition of LCE pillars. A LCE film covered with well-arranged micro-pillars, when heated up to its N-I phase transition, should show

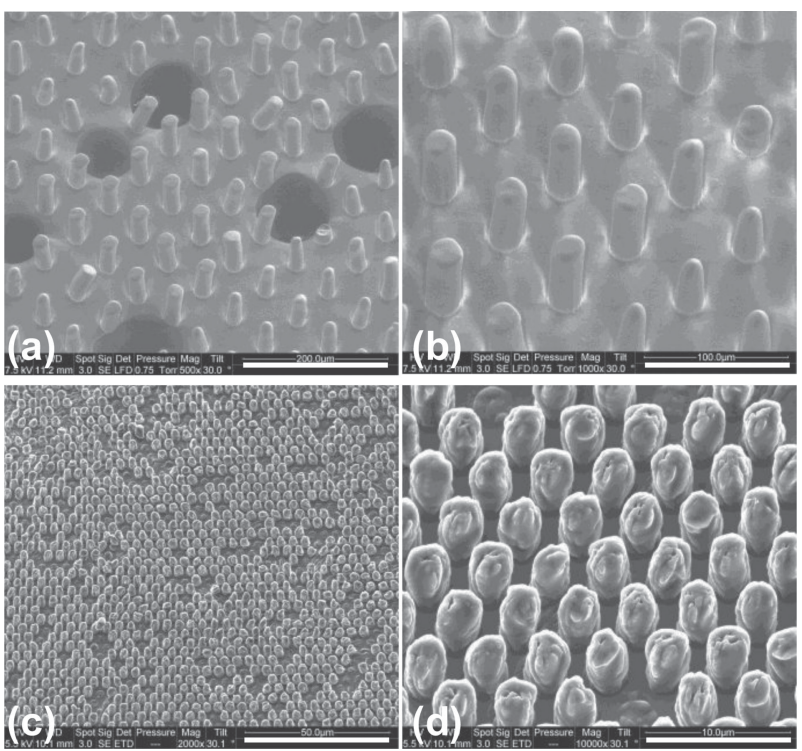

Figure 5. SEM images of structured surface with hexagonally-arranged micro-pillars. a,b) surface based on E-VC4 $(n=3)$, pillar size: diameter $=$ $20 \mu \mathrm{m}$, length $=75 \mu \mathrm{m}$, spacing $=60 \mu \mathrm{m} ; \mathrm{c}, \mathrm{d})$ surface based on E-VC8 $(n=3)$, pillar size: diameter $=3 \mu \mathrm{m}$, length $=6 \mu \mathrm{m}$, spacing $=1.5 \mu \mathrm{m}$. Scale bar: (a) $200 \mu \mathrm{m}$; (b) $100 \mu \mathrm{m}$; (c) $50 \mu \mathrm{m}$; (d) $10 \mu \mathrm{m}$. 

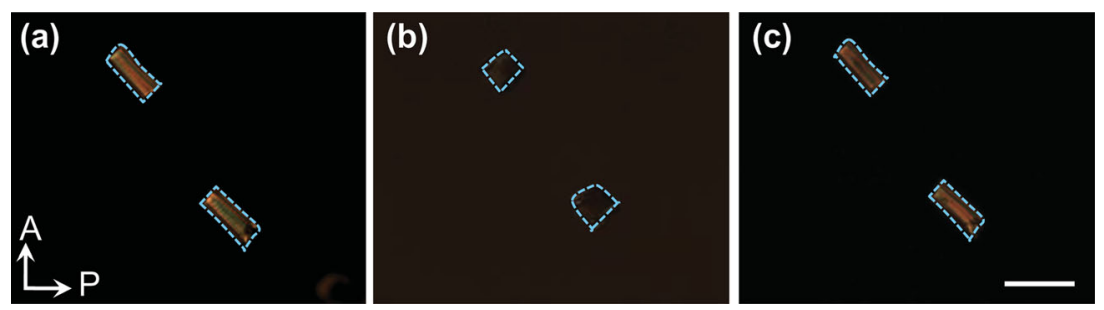

Figure 6. Micrographs of pillars (E-VC4 $(n=3), 10 \%$ crosslinker) observed at different temperatures. The pillars were cut off from the structured surfaces and suspended in silicone oil to observe the shape change with temperature under polarizing optical miscroscope. The pillars were heated at a) $30^{\circ} \mathrm{C}$, b) $96^{\circ} \mathrm{C}$, and then cooled back to c) $48^{\circ} \mathrm{C}$. The dotted lines outline the shape of the pillars to guide the eye. Scale bar: $100 \mu \mathrm{m}$. A: Analyzer; P: Polarizer.

a change of surface roughness due to the contraction of the pillars. This responsive surface should enable us to control the physical properties of the surfaces, such as the wetting (Figure 7a).

We chose VC8 $(n=3)$ LC monomer to prepare the responsive surface, because the corresponding LCE had relatively low $T_{\mathrm{NI}}$ and large contraction, i.e., $76{ }^{\circ} \mathrm{C}$ and $34 \%$, respectively. As shown in Figure $5 \mathrm{c}, \mathrm{d}$, microstructured surfaces were successfully obtained, which were covered by hexagonally-arranged pillars with dimensions of diameter $=3 \mu \mathrm{m}$, length $=6 \mu \mathrm{m}$, and spacing $=1.5 \mu \mathrm{m}$. The pillars were deformed to some extent because E-VC8 $(n=3)$ was softer than E-VC4 $(n=3)$ (much softer than E-A444);[16] the deformations might have been generated when the mold was peeled off. At room temperature, this LCE with structured surface had a water contact angle, WCA, of $127^{\circ}$. Theoretically, according to the Cassie model, WCA (noted as $\left.\theta^{*}\right)$ should be $125^{\circ}$, with $\cos \theta^{*}=-1+\Phi_{\mathrm{s}}(\cos \theta+1),{ }^{[17]}$ in which $\Phi_{\mathrm{s}}$ was the area fraction of the asperities, $\theta$ was the WCA of the flat surface (here $\Phi_{\mathrm{s}}=0.4, \theta=87^{\circ}$ ). On the other hand, the WCA for E-VC8 $(n=3)$ with a flat surface was $87^{\circ}$. When the temperature was gradually raised to above the $T_{\mathrm{NI}}$ of the LCE $\left(76^{\circ} \mathrm{C}\right)$, the WCA of the flat surface just slightly decreased, reaching $84^{\circ}$ at $85^{\circ} \mathrm{C}$. In contrast, for the first heating cycle, the WCA of the microstructured surface decreased from $127^{\circ}$ at $40{ }^{\circ} \mathrm{C}$ to $86^{\circ}$ at $81^{\circ} \mathrm{C}$ (Figure $7 \mathrm{~b}$ ).

When the responsive surface was cooled back to room temperature, WCA was $114^{\circ}$, not fully back to $\sim 127^{\circ}$. However, in the following thermal cycles, good reversibility was observed; WCA changed from $\sim 110^{\circ}$ to $86^{\circ}$ when the structured surface was subjected to $35^{\circ} \mathrm{C}$ and $80{ }^{\circ} \mathrm{C}$, respectively (Figure $7 \mathrm{c}$ ). Much larger amplitude between the two states could be obtained by optimizing the size and spacing of the pillars. ${ }^{[4 g, 18]}$

We should emphasize that the observed hydrophobicity change for the responsive surface made of LCE resulted from the roughness change of the surface owing to the contraction of the micropillars, which is different from the change of chemical properties used in the previously developed systems. ${ }^{[4]}$ Our work clearly proves that the physical properties of the surface such as wetting could be well tuned by reversibly changing the surface roughness. Responsive surfaces with biomimetic microstructures and smart response to external stimuli should provide a general means to design novel functional materials and devices.

\section{Conclusions}

By introducing carbonate group instead of the ester group, we have successfully synthesized side-on nematic LC monomers and LCEs with low $T_{\mathrm{NI}}$, lower than $100^{\circ} \mathrm{C}$. Moreover, extending

(a)
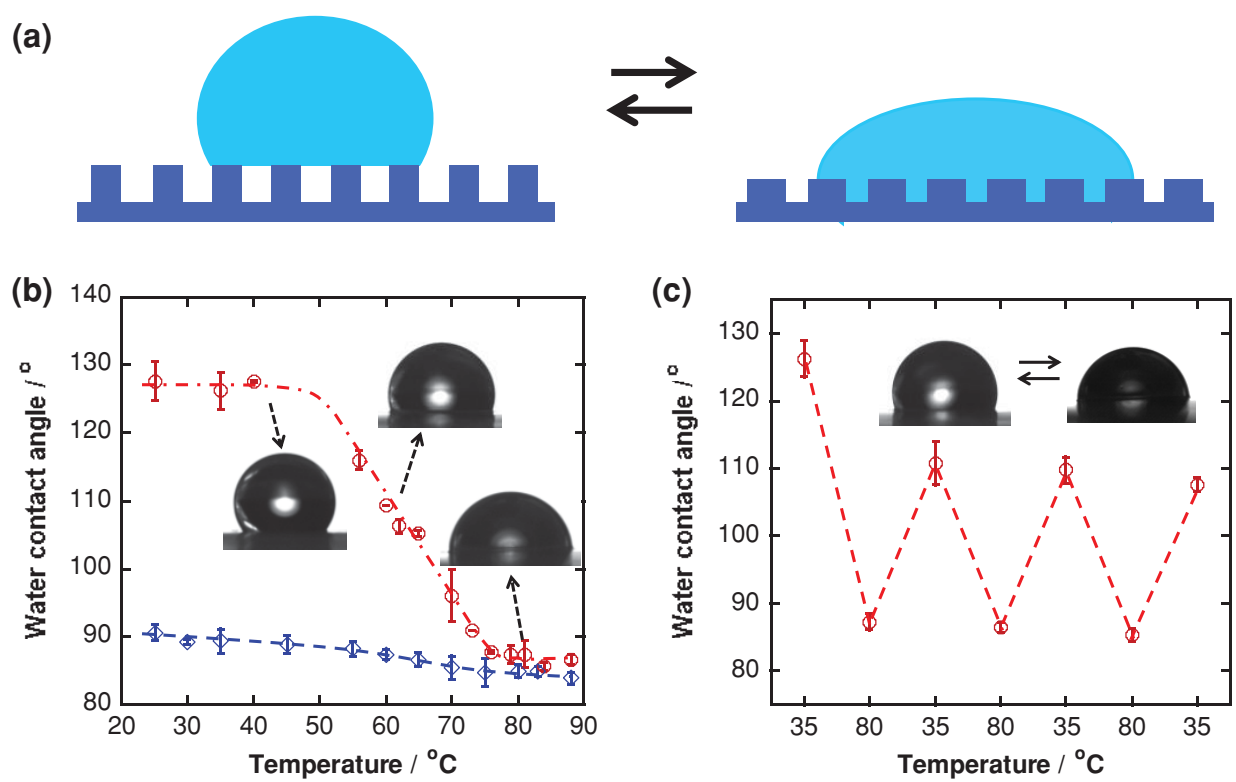

Figure 7. a) A scheme describing the control of the wetting properties by tuning the surface roughness. b) Hydrophobicity changes for the responsive surface, E-VC8 $(n=3)$ covered with micro-pillars, at different temperatures. structured surface; flat surface. c) Cyclic measurements of the WCA for a structured surface switching between $35^{\circ} \mathrm{C}$ and $80^{\circ} \mathrm{C}$. Insets are representative profiles of a water droplet on the surfaces. 
the length of the terminal chains, which were grafted on two ends of the mesogenic unit, can further lower the $T_{\mathrm{NI}}$ of the LCEs up to $\sim 76^{\circ} \mathrm{C}$. These LCEs have been used to create microtextured surfaces, covered by well-arranged micropillars, by using a replica molding technique. Each pillar behaved as a single micro-actuator and reversibly contracted along the axis of the cylinder, resulting in a responsive change of the surface roughness that gave us the opportunity to control the physical properties of the surfaces, and in particular the wetting properties. The water contact angle (WCA) of the structured surface could be switched between $110^{\circ}$ and $86^{\circ}$, when the responsive surface underwent cyclic temperature changes between 35 and $80^{\circ} \mathrm{C}$. The functionality of the surfaces relied on both the microstructure and the responsiveness of the materials, which should serve as a paradigm to develop novel functional systems.

\section{Experimental Section}

Synthesis of Vinyl and Allyl Carbonate LC Monomers: The monomers have been prepared using the synthetic routes described in Figure 1. The synthesis of $3^{\prime \prime}$-vinylcarbonyloxypropyl 2,5-di (4'-butyloxybenzoyloxy) benzoate as a representative example is presented below.

The 2,5-di (4'-butyloxybenzoyloxy)benzoic acid $(\mathbf{6}, \mathbf{C} 4)$ was synthesized by a typical process, as described elsewhere. ${ }^{[8 b]}$ We simply present here the reaction protocol. To a stirred solution of 2,5-dihydroxybenzoic acid (1) in dimethylformamide (DMF) was added solid $\mathrm{NaHCO}_{3}$. The mixture was heated and stirred at $70{ }^{\circ} \mathrm{C}$ for $1 \mathrm{~h}$. Benzyl bromide (2) was added, and the mixture was heated for $7 \mathrm{~h}$. After the purification process, benzyl 2,5-dihydroxybenzoate (3) was obtained. A solution of $\mathbf{3}$, 4-butyloxybenzoic acid (4, C4), N,N-dicyclohexylcarbodiimide (DCC), and pyrrolidinopyridine in dichloromethane was stirred at room temperature for $12 \mathrm{~h}$. The target product, benzyl 2,5-di (4'-butyloxybenzoyloxy) benzoate $(5, \mathrm{C} 4)$, was then hydrogenated to produce 2,5-di (4'-butyloxybenzoyloxy) benzoic acid $(6, \mathrm{C} 4)$.

(3"-hydroxypropyl) 2,5-di(4'-butyloxybenzoyloxy) benzoate (8, C4, n $=3)$ was synthesized as follows. To a solution of $6(R=$ butyloxy; $2 \mathrm{~g}$, $3.9 \mathrm{mmol})$ in DMF $(15 \mathrm{~mL})$ was added solid $\mathrm{NaHCO}_{3}(1 \mathrm{~g}, 11.8 \mathrm{mmol})$. The mixture was heated and stirred at $70^{\circ} \mathrm{C}$ for $1 \mathrm{~h}$. 3-bromo-1-propanol $(7, n=3)(0.7 \mathrm{ml}, 7.74 \mathrm{mmol})$ was added, and the mixture was heated for $7 \mathrm{~h}$ at $70^{\circ} \mathrm{C}$. The reaction mixture was cooled, diluted with water $(100 \mathrm{~mL})$, and extracted twice with $100 \mathrm{~mL}$ of a $50: 50$ (volume ratio) hexane/ethyl acetate mixture. The organic phases were washed with water $(100 \mathrm{~mL})$ and dried over $\mathrm{Na}_{2} \mathrm{SO}_{4}$. After evaporation of the solvents, the crude product (3"-hydroxypropyl) 2,5-di(4'-butyloxybenzoyloxy)benzoate $(8, \mathbf{C} 4, n=3)$ was recrystallized twice from absolute ethanol $(20 \mathrm{~mL})$. ' $\mathrm{H}$ NMR spectra of the compound is given in Figure S1 (Supporting Information).

3"-vinylcarbonyloxypropyl 2,5-di(4'-butyloxybenzoyloxy)benzoate (10, C4, $n=3)$. (3"'-hydroxypropyl) 2,5-di(4'-butyloxybenzoyloxy) benzoate $(8, \mathrm{C} 4, n=3)$ (2 $\mathrm{g}, 3.47 \mathrm{mmol}$ ) was dissolved in dichloromethane $(40 \mathrm{~mL})$. The solution in a flask was stirred and cooled in an ice bath. The air in the flask was removed by bubbling argon gas for $10 \mathrm{~min}$. Under argon, to the solution were added successively pyridine $(0.4 \mathrm{~mL})$ and vinyl chloroformate (9) $(0.4 \mathrm{~mL}, 4.38 \mathrm{mmol})$ via syringe. ${ }^{[19]}$ After $1 \mathrm{~h}$, the ice bath was removed, and the reaction was continued for another $5 \mathrm{~h}$. The reaction mixture was diluted with dichloromethane $(200 \mathrm{~mL})$, and extracted with water $(200 \mathrm{~mL})$. The organic phase was dried over $\mathrm{Na}_{2} \mathrm{SO}_{4}$. After evaporation of the solvents, the crude product of 3"-vinylcarbonyloxypropyl 2,5-di (4'-butyloxybenzoyloxy)benzoate (10, C4, $n=3$ ) was recrystallized 3 times from absolute ethanol $(15 \mathrm{~mL})$. ${ }^{1} \mathrm{H}$ NMR spectra is presented in Supporting Information Figure S2a. Elemental analysis: calculated for $\mathrm{C}_{35} \mathrm{H}_{38} \mathrm{O}_{11}$ : $\mathrm{C}, 66.18 ; \mathrm{H}, 5.99$. Found: C, 66.29; H, 6.01 . (3"-allylcarbonyloxypropyl) 2,5-di (4'-butyloxybenzoyloxy) benzoate $(12, \mathrm{C} 4, n=3)$ was synthesized by a similar procedure, using allyl chloroformate (11) instead of 10 . The related ${ }^{1} \mathrm{H}$ NMR spectra is shown in Supporting Information Figure S2b. Elemental analysis: calculated for $\mathrm{C}_{36} \mathrm{H}_{40} \mathrm{O}_{11}$ : $\mathrm{C}, 66.60 ; \mathrm{H}, 6.17$. Found: $\mathrm{C}, 66.60 ; \mathrm{H}, 6.18$.

Following this protocol, series of vinyl and allyl carbonate monomers were synthesized by varying the spacer length $(n=2,3$ and 6 in 10 and 12) and the length of the terminal alkyl chains, which are grafted on the mesogens ( $R$ in 10 and 12). Most of them exhibit a nematic mesophase with $T_{\mathrm{NI}}$ lower than $100^{\circ} \mathrm{C}$. The carbonate LC monomers are noted VCX $(n=\gamma)$ or $\mathrm{ACx}(n=\gamma)$, where $\mathrm{V}$ or $\mathrm{A}$ indicates vinyl or allyl monomer, $x$ and $y$ are the number of carbon in the end alkyl chains and in the spacer (between the benzoate group and carbonate group), respectively.

Preparation of Monodomain LCE Films: Mixtures of carbonate LC monomer (90 mol\%), divinyl sebacate (chemical crosslinker, 10 mol\%), and 2-benzyl-2-(dimethylamino)-4-morpholinobutyrophenone (photoinitiator, $0.3 \mathrm{~mol} \%$ of the total reactants) were used in the preparation of aligned LCE films. Mixtures, heated in their isotropic phase, were filled by capillarity in rubbed polyimide-coated glass cells of $20 \mu \mathrm{m}$ gap (commercial Instec LC cells). The filled cells were slowly cooled down at $-1{ }^{\circ} \mathrm{C} / \mathrm{min}$ to the nematic phase of the mixture to achieve planar alignment. The cooling and the subsequent UV irradiation were carried under a stream of nitrogen (using a zip-lock bag), ${ }^{[1]}{ }^{[1]}$ to ensure an inert atmosphere during the radical polymerization. After UV irradiation $\left(365 \mathrm{~nm}, 30 \mathrm{~mW} / \mathrm{cm}^{2}\right.$ ) for $5 \mathrm{~h}$, the free-standing, aligned LCE films were obtained by dissolving the glass windows of the cells with $40 \%$ aqueous hydrofluoric acid solution. ${ }^{[20]}$

LCE samples are noted with "E" in front of the name of LC monomers. Liquid crystalline polymers (LCPs) were synthesized by photopolymerization of the monomers directly in the crucible used for differential scanning calorimetry (DSC) in absence of chemical crosslinker to compare their $T_{N I}$ with those of LC monomers and LCEs. LCP samples are noted with "P" in front of the name of LC monomers.

Synthesis of LCE-Based Structured Surfaces: Responsive surfaces based on LCEs were prepared by photopolymerizing the same LC mixtures used above for the LCE films. Using a set-up described previously, ${ }^{[1]}$ LCE surfaces covered with micrometer-sized pillars of various shapes and sizes were obtained.

In practice, a small amount of the LC mixture including crosslinker and photoinitiator was heated to the isotropic phase on a microscope slide positioned atop a rare earth permanent magnet $(=1 \mathrm{~T} \mathrm{NdFeB}$ rare earth magnet). The PDMS soft mold, prepared through a softlithography technique, ${ }^{[11 a, 21]}$ was then gently pressed down on the melted sample, which filled the inner structure of the mold. To keep an inert atmosphere for the radical polymerization, the whole setup was then sealed in a zip-lock bag under a nitrogen flow. The temperature was then slowly decreased $\left(-1{ }^{\circ} \mathrm{C} / \mathrm{min}\right)$ down to the temperature at which the mixture is in its nematic phase. During the cooling process, the applied magnetic field ensured the alignment of the nematic director parallel to the long axis of the pillars. The sample was then irradiated through the mold using a UV lamp for $5 \mathrm{~h}$ to promote the photopolymerization and crosslinking reaction of the monomer mixture. After cooling to room temperature, the PDMS mold was peeled off, leaving a thin glassy polymer film covered by a regular array of micropillars.

Characterization: ${ }^{1} \mathrm{H}$ NMR spectra were recorded on a Bruker $300 \mathrm{MHz}$ spectrometer to confirm the molecular structures of the synthesized alcohols (8), and final monomers (10 and 12). All spectra were run in chloroform-d $\left(\mathrm{CDCl}_{3}\right)$ solution. The mesomorphic properties of the monomers, LCPs, and LCEs were studied by thermal optical polarizing microscopy (Leitz Ortholux microscope equipped with a Mettler FP82 hot stage) and differential scanning calorimetry (Perkin-Elmer DSC7). The heating and cooling rates were $5{ }^{\circ} \mathrm{C} / \mathrm{min}$. The contraction of macroscopic LCE films and micron-size pillars were measured by the dimension change of the samples in the alignment direction of side-on mesogens. The contraction was calculated by $\left(L-L_{0}\right) / L_{0}$, in which $L$ and $L_{0}$ are the length of the samples at room temperature and above $T_{\mathrm{N}}$, respectively. The scanning electron microscopy (SEM) images were obtained at room temperature for samples tilted at a $30^{\circ}$ angle, on a Quanta 200 
FEG high-resolution environmental scanning electron microscope (FEI company). It might be noticed that the small pillars were sputter coated with carbon to avoid any degradation during observation. Water contact angles (WCAs) of the responsive surfaces at a given temperature were measured on a Digidrop contact angle meter (GBX, France). $4 \mu \mathrm{L}$ MilliQ water droplets were dropped carefully onto the surfaces of LCEs, which were pre-heated to the required temperature.

\section{Supporting Information}

Supporting Information is available from the Wiley Online Library or from the author.

\section{Acknowledgements}

This research was supported by ANR (ANR-10-INTB-0904) and a PICSCNRS project. We thank Mrs. Sylvie Dubruille, Dr. Min-Hui Li and Dr. Vincent Semetey for their help with NMR, DSC, and water contact angle measurements, respectively.

[1] a) P. Fratzl, J. R. Soc. Interface 2007, 4, 637; b) C. Sanchez, H. Arribart, M. M. Giraud Guille, Nat. Mater. 2005, 4, 277; c) P. Fratzl, F. G. Barth, Nature 2009, 462, 442.

[2] a) P. Vukusic, J. R. Sambles, Nature 2003, 424, 852; b) L. Feng, S. Li, Y. Li, H. Li, L. Zhang, J. Zhai, Y. Song, B. Liu, L. Jiang, D. Zhu, Adv. Mater. 2002, 14, 1857; c) Y. Zhao, Z. Xie, H. Gu, Z. Zhu, Z. Gu, Chem. Soc. Rev. 2012, 41, 3297; d) E. Arzt, S. Gorb, R. Spolenak Proc. Natl. Acad. Sci. USA 2003, 100, 10603.

[3] a) P. Roach, N. J. Shirtcliffe, M. I. Newton, Soft Matter 2008, 4, 224; b) L. Jiang, L. Zhao, J. Zhai, Angew. Chem. Int. Ed. 2004, 116, 4438; c) L. Zhang, Z. Zhou, B. Cheng, J. M. DeSimone, E. T. Samulski, Langmuir 2006, 22, 8576; d) X. Liu, Y. Liang, F. Zhou, W. Liu, Soft Matter 2012, 8, 2070; e) X.-M. Li, D. Reinhoudt, M. Crego-Calama, Chem. Soc. Rev. 2007, 36, 1350.

[4] a) F. Xia, Y. Zhu, L. Feng, L. Jiang, Soft Matter 2009, 5, 275; b) J. Malm, E. Sahramo, M. Karppinen, R. H. A. Ras, Chem. Mater. 2010, 22, 3349; c) R. B. Pernites, R. B. Ponnapati, R. C. Advincula Adv. Mater. 2011, 28, 3207; d) H. S. Lim, D. Kwak, D. Y. Lee, S. G. Lee, K. Cho, J. Am. Chem. Soc. 2007, 129, 4128; e) X. Feng, L. Feng, M. Jin, J. Zhai, L. Jiang, D. Zhu, J. Am. Chem. Soc. 2004, 126, 62; f) C. Li, R. Guo, X. Jiang, S. Hu, L. Li, X. Cao, H. Yang, Y. Song, Y. Ma, L. Jiang, Adv. Mater. 2009, 21, 4254.

[5] a) B. N. J. Persson, O. Albohr, U. Tartaglino, A. I. Volokitin, E. Tosatti, J. Phys.: Condens. Matter 2005, 17, R1; b) A. G. Peressadko, N. Hosoda, B. N. J. Persson, Phy. Rev. Lett. 2005, 95, 124301.

[6] a) M. C. Camacho-Lopez, H. Finkelmann, P. Palffy-Muhoray, M. Shelley, Nat. Mater. 2004, 3, 307; b) M.-H. Li, P. Keller, Philos. Trans. R. Soc. A 2006, 364, 2763; c) C. L. van Oosten, W. M. Bastiaansen, D. J. Broer, Nat. Mater. 2009, 8, 677; d) T. Ikeda, J. Mamiya, Y. Yu, Angew. Chem. Int. Ed. 2007, 46, 506; e) H. Yu, T. Ikeda, Adv. Mater. 2011, 23, 2149; f) A. Sánchez-Ferrer, T. Fischl, M. Stubenrauch, H. Wurmus, M. Hoffmann, H. Finkelmann, Macromol. Chem. Phys. 2009, 210, 1671; g) M.-H. Li, P. Keller, B. Li,
X. Wang, M. Brunet, Adv. Mater. 2003, 15, 569; h) M.-H. Li, P. Keller, J. Yang, P.-A. Albouy, Adv. Mater. 2004, 16, 1922.

[7] J. P. Cotton, F. Hardouin, Prog. Polym. Sci. 1997, 22, 795

[8] a) J. Küpfer, H. Finkelmann, Macromol. Chem., Rapid Commun. 1991, 12, 717; b) D. L. Thomsen III, P. Keller, J. Naciri, R. Pink, H. Jeon, D. Shenoy, B. R. Ratna, Macromolecules 2001, 34, 5868; c) Y. Sawa, F. Ye, K. Urayama, T. Takigawa, V. Gimenez-Pinto, R. L. B. Selinger, J. V. Selinger, Proc. Natl. Acad. Sci. USA 2011, 108, 6364.

[9] a) C. Ohm, M. Brehmer, R. Zentel, Adv. Mater. 2010, 22, 3366; b) H. Yang, G. Ye, X. Wang, P. Keller, Soft Matter 2011, 7, 815; c) J. Cui, D.-M. Drotlef, I. Larraza, J. P. Fernández-Blázquez, L. F. Boesel, C. Ohm, M. Mezger, R. Zentel, A. del Campo, Adv. Mater. 2012, 24, 4601.

[10] a) C. Ohm, C. Serra, R. Zentel, Adv. Mater. 2010, 21, 4859; b) C. Ohm, E.-K. Fleischmann, I. Kraus, C. Serra, R. Zentel, Adv. Funct. Mater. 2010, 20, 4314; c) C. Ohm, N. Kapernaum, D. Nonnenmacher, F. Giesselmann, C. Serra, R. Zentel, J. Am. Chem. Soc. 2011, 133, 5305; d) E.-K. Fleischmann, H.-L. Liang, N. Kapernaum, F. Giesselmann, J. Lagerwall, R. Zentel, Nat. Commun. 2012, 3, 1178

[11] a) A. Buguin, M.-H. Li, P. Silberzan, B. Ladoux, P. Keller, J. Am Chem. Soc. 2006, 128, 1088; b) H. Yang, A. Buguin, J.-M. Taulemesse, K. Kaneko, S. Méry, A. Bergeret, P. Keller, J. Am. Chem. Soc. 2009, 131,15000 ; c) Y. Sun, J. S. Evans, T. Lee, B. Senyuk, P. Keller, S. He, I. I. Smalyukh, Appl. Phys. Lett. 2012, 100, 241901.

[12] a) H. Ringsdorf, A. Schneller, Makromol. Chem., Rapid Commun. 1982, 3, 557; b) S. J. Sun, H. P. Cheng, T. C. Chang, C. H. Chang, Euro. Polym. J. 1995, 31, 825; c) C. T. Imrie, F. E. Karasz, G. S. Attard, Macromolecules 1993, 26, 3803.

[13] Q. Qian, J. Chen, M.-H. Li, P. Keller, D. He, J. Mater. Chem. 2012 22, 4669 .

[14] F. Hessel, H. Finkelmann, Polym. Bull. 1985, 14, 375

[15] a) C. Pugh, R. R. Schrock, Macromolecules 1992, 25, 6593; b) S. V. Arehart, C. Pugh, J. Am. Chem. Soc. 1997, 119, 3027; c) G.-H. Kim, C. Pugh, S. Z. D. Cheng, J. Polym. Sci., Part B: Polym. Phys. 2001, 39, 3029.

[16] E-VC8 $(n=3)$ could not be used to prepare surface with long pillars (dimension: diameter $=20 \mu \mathrm{m}$, length $=100 \mu \mathrm{m}$, spacing $=$ $100 \mu \mathrm{m})$. When peeling off the mold, most the pillars made of E-VC8 $(n=3)$ were broken, because of its softness and lacking sufficient mechanical strength even in the glassy state.

[17] a) A. B. D. Cassie, S. Baxter, Trans. Faraday Soc. 1944, 40, 546; b) M. Callies, D. Quéré, Soft Matter 2005, 1, 55; c) A. Lafuma, D. Quéré, Nat. Mater. 2003, 2, 457.

[18] a) Z. Yoshimitsu, A. Nakajima, T. Watanabe, K. Hashimoto, Lang muir 2002, 18, 5818; b) N. A. Patankar, Langmuir 2004, 20, 7097 c) T. Sun, G. Wang, H. Lin, L. Feng, L. Jiang, D. Zhu, J. Am. Chem. Soc. 2003, 125, 14996; d) B. Bhushan, Y. C. Jung, J. Phys.: Condens. Matter 2008, 20, 225010

[19] a) G. Meunier, P. Hémery, S. Boileau, J.-P. Senet, H. Chéradame, Polymer 1982, 23, 849; b) F. Kassir, S. Boivin, S. Boileau, H. Chéradame, G. P. Wooden, R. A. Olofson, Polymer 1985, 26, 443; c) C. Heller, M. Schwentenwein, G. Russmüller, T. Koch, D. Moser, C. Schopper, F. Varga, J. Stampfl, R. Liska, J. Polym. Sci. Part A: Polym. Chem. 2011, 49, 650; d) B. Husár, R. Liska, Chem. Soc. Rev. 2012, 41, 2395.

[20] This process would not lead to the hydrolysis of carbonate group in the LCEs. The LCEs before and after dissolving the glass cell had the same $T_{\mathrm{Nl}}$, as confirmed by thermal optical polarizing microscopy.

[21] Y. Xia, G. M. Whitesides, Angew. Chem. Int. Ed. 1998, 37, 550. 